\title{
INVESTIGATION OF THE INFLUENCE OF
}

\section{THERMOMECHANICAL TREATMENT ON THE STRUCTURAL- PHASE STATE AND MECHANICAL PROPERTIES OF A VZH171 ALLOY}

\author{
S. A. Bozhko, ${ }^{1}$ Yu. R. Kolobov, ${ }^{1,2}$ S. S. Manokhin, ${ }^{2}$ S. V. Ovsepyan, ${ }^{3}$ \\ D. M. Levin, ${ }^{4}$ A. Yu. Tokmacheva-Kolobova, ${ }^{2}$ and A. E. Ligachev ${ }^{5}$
}

An analysis of the influence of thermomechanical treatment (TMT) (rolling to a strain degree of 50\%, annealing at a temperatures of $600-1200^{\circ} \mathrm{C}, 1 \mathrm{~h}$ ) on the microstructure and phase composition of a VZh171 alloy in the initial state and after its bulk nitriding is performed. It is shown that nitriding leads to an increase in the thermal stability of the alloy microstructure. While a primary recrystallization and formation of finegrained structure occurs in an non-nitrided alloy quite intensively at the temperature above $1000^{\circ} \mathrm{C}$, the process of collective recrystallization does not gain any significant development in the nitrided alloy even at an annealing temperature of $1200^{\circ} \mathrm{C}$, and the microstructure remains ultrafine-grained (grain size 5-10 $\mu \mathrm{m}$ ). The mechanical properties of the nitrided and non-nitrided alloy are investigated. It is established that nitriding has no significant effect on the alloy strength at room temperature. In the tests at $800^{\circ} \mathrm{C}$, the maximum strength and the minimum plasticity are demonstrated by the nitrided alloy after rolling and subsequent annealing at $600^{\circ} \mathrm{C}$. The optimum ratio of the ultimate tensile strength (480 MPa) to plasticity (elongation to fracture $23 \%$ ) is observed in the nitrided alloy after TMT and annealing at $800^{\circ} \mathrm{C}$.

Keywords: thermomechanical treatment, bulk nitriding, diffusion-induced atomic fluxes, diffusion-controlled processes, structure, phase composition, dispersion hardening, mechanical properties, electron microscopy.

Research and development of new refractory alloys aimed at increasing the maximum temperatures of their service and introducing them into industrial practices are the most important challenges of the present-day materials science $[1,2]$. Now high-temperature alloys based on nickel, cobalt, and iron with a complex of additional alloying elements are widely applied in the production of parts and units of gas-turbine aircraft engines.

The efficiency of traditional high-temperature alloys $[1,2]$ at high temperatures is affected by the dispersion and solid-solution hardening and their combinations. Note that dispersion hardening can be implemented in two ways: both by the particles of intermetallic compounds formed by the alloy components and/or by the particles of binary or more complex metal- and non-metallic compounds found in the solid solution or introduced into the material during a special chemical heat treatment (CHT).

${ }^{1}$ National Research University "Belgorod State University", Belgorod, Russia, e-mail: sambusa@inbox.ru; kolobov@bsu.edu.ru; ${ }^{2}$ Institute of Problems of Chemical Physics of the Russian Academy of Sciences, Chernogolovka, Russia, e-mail: manohin@bk.ru; anastasiia.misis@gmail.com; ${ }^{3}$ All-Russian Institute of Aviation Materials, Moscow, Russia, e-mail: ovsepyan64@gmail.com; ${ }^{4}$ Tula State University, Tula, Russia, e-mail: danlevin48@gmail.com; ${ }^{5}$ Prokhorov General Physics Institute of the Russian Academy of Sciences, Moscow, Russia, e-mail: carbin@yandex.ru. Translated from Izvestiya Vysshikh Uchebnykh Zavedenii, Fizika, No. 12, pp. 134-140, December, 2019. Original article submitted November 12, 2019. 
For the temperatures lower than $1000^{\circ} \mathrm{C}$ in modern gas turbine engines, $\mathrm{Ni}$ - or Co-based alloys with multiple alloying admixtures are used, in which case solid-solution hardening occurs due to a high content of the atoms of highmelting elements in the solid solution (e.g., VZh145, HS 188 alloys, etc. [3, 4]). However further complication of the chemical composition of these alloys for the purpose of increasing their working temperatures is not worthwhile, because of the attained limit of rational solid solution alloying above which there is precipitation of typologically closepacked phases (TCP-phase) causing embrittlement of the alloys. Furthermore, an increase in the concentration of atoms of high-melting elements in the nickel base gives rise to a significant increase in the alloy density.

In the dispersion-hardended alloys based on $\mathrm{Ni}$ with the working temperature up to $1050^{\circ} \mathrm{C}$ (VZh98, VZh159, HS 282, etc.), thermal stability is achieved due to complex alloying of the solid solution and formation of disperse particles of the strengthening $\gamma^{\prime}-\mathrm{Ni}_{3} \mathrm{Al}$ phases with the $L 1_{2}$ superstructure [5-7]. These particles are coherent; they are located in the bulk of the material and ensure dispersion hardening of the alloys. However with an increase in the working temperature above $1100^{\circ} \mathrm{C}$ there is an intensive softening of the alloys due to the developing processes of coalescence and dissolution of fine particles of the strengthening $\gamma^{\prime}$-phase.

The mechanism of dispersion hardening of alloys after their chemical heat treatment was implemented in the alloys strengthened by oxide particles (ODS-alloys); however an availability of a number of essential disadvantages, namely anisotropy and relatively low ultimate tensile strength (UTS), limit the fields of their application [8]. Carbide hardening turned out to be effective only up to the working temperatures up to $800^{\circ} \mathrm{C}$, above which the strengthening carbide particles begin dissolving quite intensively.

The use of nitride particles as the strengthening phase, which are formed in the course of high-temperature bulk (internal) nitriding turned out to be a promising approach for increasing the thermal stability of nickel alloys. The most effective hardening takes place in the cases where nitrides with high thermodynamic stability are formed, which are evenly distributed throughout the volume of the matrix. A rational selection of composition and structure of the alloys offers a possibility of ensuring such important technical characteristics of the resulting high-temperature alloys as weldability and their capacity to plastic deformation [9]. One should also note such common disadvantage of the internal nitriding method as the formation of a homogeneous structure only in the diffusion zone within which the nitrogen atoms penetrate the processed metal. For this reason, the thickness of the products manufactured from the nitride-strengthened alloys cannot exceed $1.5-2 \mathrm{~mm}$.

The high-temperature alloys strengthened by internal nitriding are multicomponent materials and contain the elements with differing chemical affinity to nitrogen. The highest chemical affinity for nitrogen is demonstrated by $\mathrm{Ti}$ and Al. These elements form highly stable nitrides capable of essentially increasing the thermal stability of alloys. Contrary to this, such alloying elements as $\mathrm{Cr}$ and $\mathrm{W}$ are characterized by a low chemical affinity to nitrogen. The nitride phases formed with them become unstable when heated above $1100^{\circ} \mathrm{C}$ and decompose. The main components of the Ni and Co alloys do not form any stable nitride compounds.

The Federal State Unitary Enterprise VIAM has developed a weldable deformable high-temperature alloy of a new generation - HN29K28VMT (VZh171), whose maximum operating temperature is $1250^{\circ} \mathrm{C}$, which is $150-200^{\circ} \mathrm{C}$ higher than that of the serial alloys [10]. The structure and balanced composition were selected by the authors so that to ensure the structure stability and rule out the conditions for the formation of topologically close-packed $\varepsilon$ - and $\pi$-phase of chromium nitrides; at present the VZh171 alloy is being actively introduced in the aircraft industry [11, 12]. Nitride hardening is also used for such high-temperature nickel-based alloys as VZh155 with the operation temperatures up to $1200^{\circ} \mathrm{C}$, and $\mathrm{HS} 161$ alloy based on the $\mathrm{Co}-\mathrm{Cr}-\mathrm{Fe}$ system (operating temperatures to $1150^{\circ} \mathrm{C}$ ) [13-18], etc.

Products from the particle-hardened VZh171 alloy after its internal nitriding can be subjected to external loading and, as a result, undergo plastic deformation. This is a consequence of the operational or technological loading acting on the material during its fabrication or in the course of operation of the parts of gas turbine engines. Plastic deformation also develops due to thermomechanical treatment, which can be used as an effective method for forming an optimal microstructure and controlling the properties of high-temperature alloys. At present, there are a limited number of publications on the regularities of structural changes, features of distribution of disperse phases in the bulk and properties of the nitrided VZh171 alloy, including those after thermomechanical treatment. Therefore the purpose of this work is to study the microstructure characteristics of the high-temperature VZh171 alloy before and after its nitriding and to determine the patterns of evolution of morphology of nitride particles in the nitrided alloy after its thermomechanical treatment according to different modes. 


\section{EXPERIMENTAL MATERIAL AND PROCEDURE}

In this study we investigated a high-temperature VZh171 alloy (1.5 mm thick sheet) based on the $33 \% \mathrm{Ni}-$ $29 \%$ Co $-29 \%$ Cr system, which was additionally alloyed with tungsten, molybdenum and titanium. The alloy specimens were investigated in the initial as-received state, after bulk nitriding, and after bulk nitriding and thermomechanical treatment.

The high-temperature bulk nitriding was carried out at a temperature of $1200^{\circ} \mathrm{C}$ for $20 \mathrm{~h}$ in a nitrogen atmosphere, followed by a homogenizing annealing at the same temperature in an argon atmosphere for $6 \mathrm{~h}$. The duration of nitriding ensures a uniform distribution of the forming nitrides throughout the entire thickness of the sheet [19-22]. Thin sections for the metallographic investigations were prepared in a LaboPol-5 facility (Struers), with a preliminary grinding depth of less than $10 \mu \mathrm{m}$. The foils were cut for the transmission electron microscopy examination at a depth of no less than $100 \mu \mathrm{m}$ from the specimen surface using an AQ300L electrodischarge machine.

The microstructure and phase composition of the specimens were studied by the methods of electron microscopy using the Quanta 600 FEG and NovaNanoSem 450 high-resolution field-emission scanning electron microscopes (equipped with an attachment for scanning transmission electron microscopy (STEM)) at the accelerating voltages of 20 and $30 \mathrm{kV}$. The structure element dimensions in the electron-microscopy images were determined using the ImageScope viewing software.

The energy dispersive elemental microanalysis was performed using an EDAX device and the Tecnailmaging\&Analysis software.

The thermomechanical treatment (TMT) of the nitrided VZh171 alloy was realized with deformation of the specimens by the sheet rolling method at room temperature in several passes. Total accumulated plastic strain by compression was $50 \%$ across the specimen thickness. Then the specimens were annealed at the temperatures of 600 , 800,1000 and $1200^{\circ} \mathrm{C}$ for $1 \mathrm{~h}$, followed by their quenching in water.

An investigation of mechanical properties was conducted using an Instron 3883 universal testing machine. The specimens for tensile tests were shaped as dumb-bell blades whose gauging sections were $16 \times 3 \times 1.5 \mathrm{~mm}$ for room temperature and $35 \times 7 \times 2 \mathrm{~mm}$ for high-temperature tests. The tests were carried out at a strain rate of $1 \cdot 10^{-3} \mathrm{~s}^{-1}$. The high-temperature tests were carried using a hinged furnace at the temperatures of 600 and $800^{\circ} \mathrm{C}$. Before tensile tests, the specimens were tempered in the furnace for $1 \mathrm{~h}$ in order to form a necessary structure and then were tested without cooling.

\section{RESULTS AND DISCUSSION}

The alloy in the as-received state has a coarse-grained structure with sparse titanium precipitates in the bulk of the grains (Fig. 1a).

Annealing of the alloy deformed to $50 \%$ at $600^{\circ} \mathrm{C}$ does not result in the development of initial recrystallization. After annealing at $800^{\circ} \mathrm{C}$, there is a weak development of the process of primary recrystallization; at the same time at the grain boundaries there is precipitation and growth of the (presumably chromium carbide) particles (Fig. 1b). As a result of annealing at $1000^{\circ} \mathrm{C}$, there is an intensive development of primary recrystallization, and the formation of ultrafine-grained structure is observed (with the grain size no more than $10 \mu \mathrm{m}$ ).

This is due to the fact that grain boundaries are pinned by the carbide particles (Fig. 1c), retarding the grain growth and transition to collective recrystallization. As the annealing temperature increases to $1200^{\circ} \mathrm{C}$, the structure becomes coarse-grained (grain size up to $200 \mu \mathrm{m}$ ), which results from a nearly complete dissolution of carbides and further grain growth (Fig. 1d).

After nitriding, the initial coarse-grained structure of the alloy is maintained and there are numerous precipitates of the dispersed phase (nitrides, carbonitrides, intermetallides) in the form of relatively large particles measuring approximately $1 \mu \mathrm{m}$ and finer precipitates (Fig. 2). The precipitates of the cruciform and three-rayed shapes predominate; there are also thin lamellar precipitates, and spherical and formless particle. The average grain size estimated as a numerical value of the distribution function mode is found to be $(70 \pm 2) \mathrm{nm}$. 

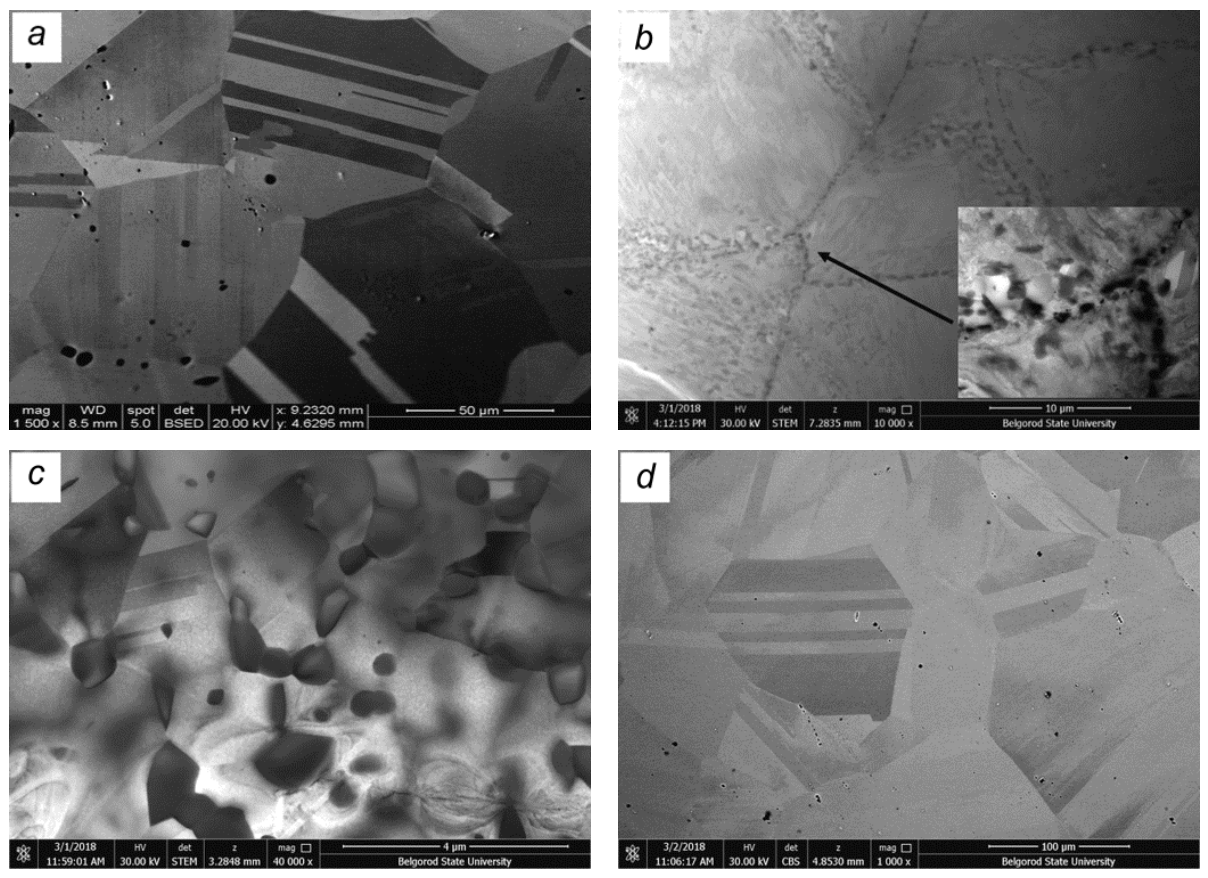

Fig. 1. SPEM images of the non-nitrided VZh171 alloy in the initial state $(a)$, after $50 \%$ rolling deformation, followed by annealing at the temperatures of $800^{\circ} \mathrm{C}(b)$, $1000^{\circ} \mathrm{C}(c)$ and $1200^{\circ} \mathrm{C}(\mathrm{d})$.
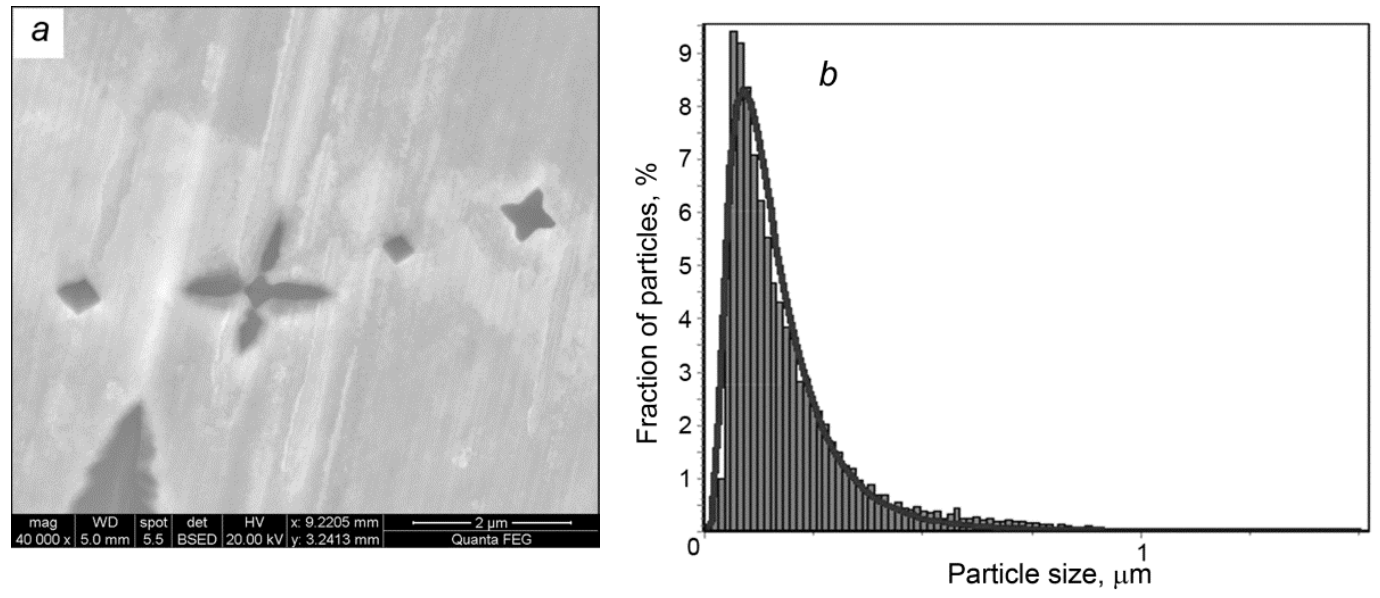

Fig. 2. Disperse phase particles in the nitrided VZh171 alloy (a). Particle size distribution bar chart $(b)$.

In order to investigate the process of recrystallization, after high-temperature bulk nitriding the VZh171 alloy specimens were subjected to rolling deformation to a strain degree of $50 \%$ and annealing at different temperatures $(800$, 1000 and $1200^{\circ} \mathrm{C}$ ). After the deformation and subsequent annealing at a temperature of $600^{\circ} \mathrm{C}$, the nitrided specimens retain their unrecrystallized structure. In contrast to non-nitrided alloy (see Fig. 1 b), after annealing at 800 and $1000^{\circ} \mathrm{C}$ the structure of the nitrided alloy is fine-grained and completely recrystallized (Fig. 3b, c). The completeness of the primary recrystallization processes in the nitrided specimens is due to a larger number of the structure defects formed during rolling in comparison with the non-nitrided alloy. 

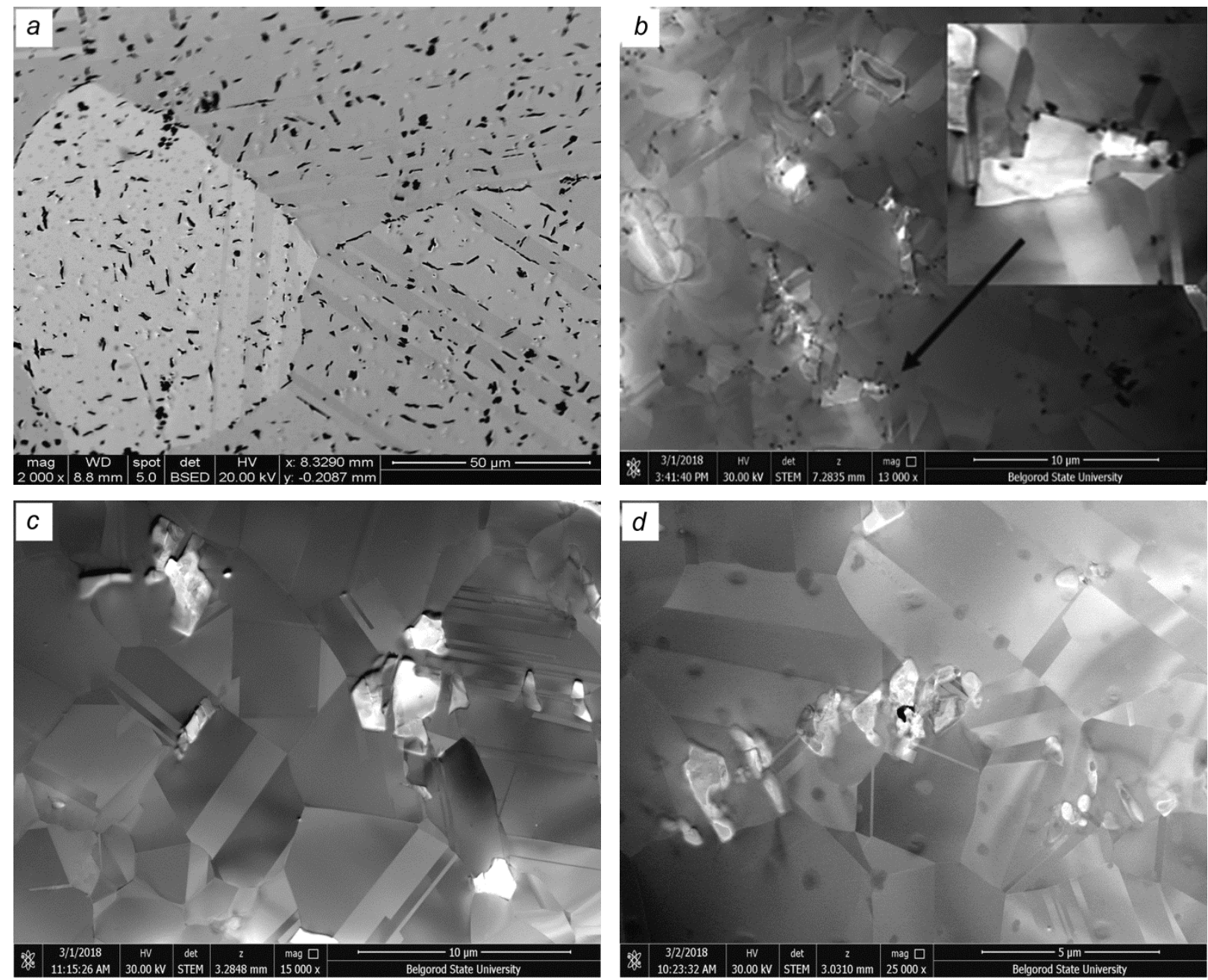

Fig. 3. SPEM image of the VZh171 alloy microstructure in the initial state after nitriding (a), after deformation by rolling to a strain degree of $50 \%$ and the subsequent annealing at the temperatures of $800^{\circ} \mathrm{C}(b), 1000^{\circ} \mathrm{C}(c)$ and $1200^{\circ} \mathrm{C}(d)$.

In the bulk of the alloy, there are also fine carbide particles on the surface of coarse nitrides, which might have nucleated under the conditions of an increased defect density. The titanium nitride particles in all the cases under study have mainly irregular shapes, frequently in the form of crushed closely located fragments formed as a result of crushing by rolling.

Unlike the non-nitrided alloy, collective recrystallization in the nitrided and deformed alloy does not significantly develop as the annealing temperature increases up to $1200^{\circ} \mathrm{C}$ (Fig. $3 d$ ) and the microstructure remains relatively fine-grained (grain size of $5-10 \mu \mathrm{m}$, which corresponds to the ultrafine-grained state). This is due to the influence of titanium nitride particles inhibiting the grain-boundary motion, which remain stable up to the matrix melting temperature.

In order to determine an interrelation between the structural-phase state and mechanical properties at high temperatures in the states under study, the alloy specimens were subjected to tensile testing at room and high temperatures. The following characteristics of mechanical properties were defined: $\sigma_{0.2}$ - offset yield stress, $\sigma_{\text {UTS }}-$ ultimate tensile strength, $\varepsilon$ - plasticity in elongation in the point of discontinuity. The measurements of mechanical properties of VZh171 separate alloy specimens were performed at room temperature and at the test temperatures of 600 
TABLE 1. Mechanical Properties of Nitrided VZh171Alloy after Annealing at Temperatures of 600 and $800^{\circ} \mathrm{C}$ Followed by Tension at These Temperatures without Cooling

\begin{tabular}{c|c|c|c|c|c}
\hline \hline $\begin{array}{c}\text { No. of } \\
\text { curve }\end{array}$ & Types of treatment & $\sigma_{0,2}, \mathrm{MPa}$ & $\begin{array}{c}\sigma_{\mathrm{UTS}}, \\
\mathrm{MPa}\end{array}$ & $\varepsilon, \%$ & $\begin{array}{c}\text { Test temperature, } \\
{ }^{\circ} \mathrm{C}\end{array}$ \\
\hline 1 & As-received & 340 & 810 & 84.0 & room temp. \\
\hline 2 & Nitriding & 440 & 814 & 22.0 & room temp. \\
\hline 3 & Nitriding, rolling to $50 \%$ & 1130 & 1130 & 0.2 & 600 \\
\hline 4 & Nitriding, rolling to $50 \%$ & 487 & 540 & 23.0 & 800 \\
\hline 5 & Nitriding & 275 & 670 & 25.6 & 600 \\
\hline 6 & Nitriding & 260 & 455 & 13.8 & 800 \\
\hline
\end{tabular}
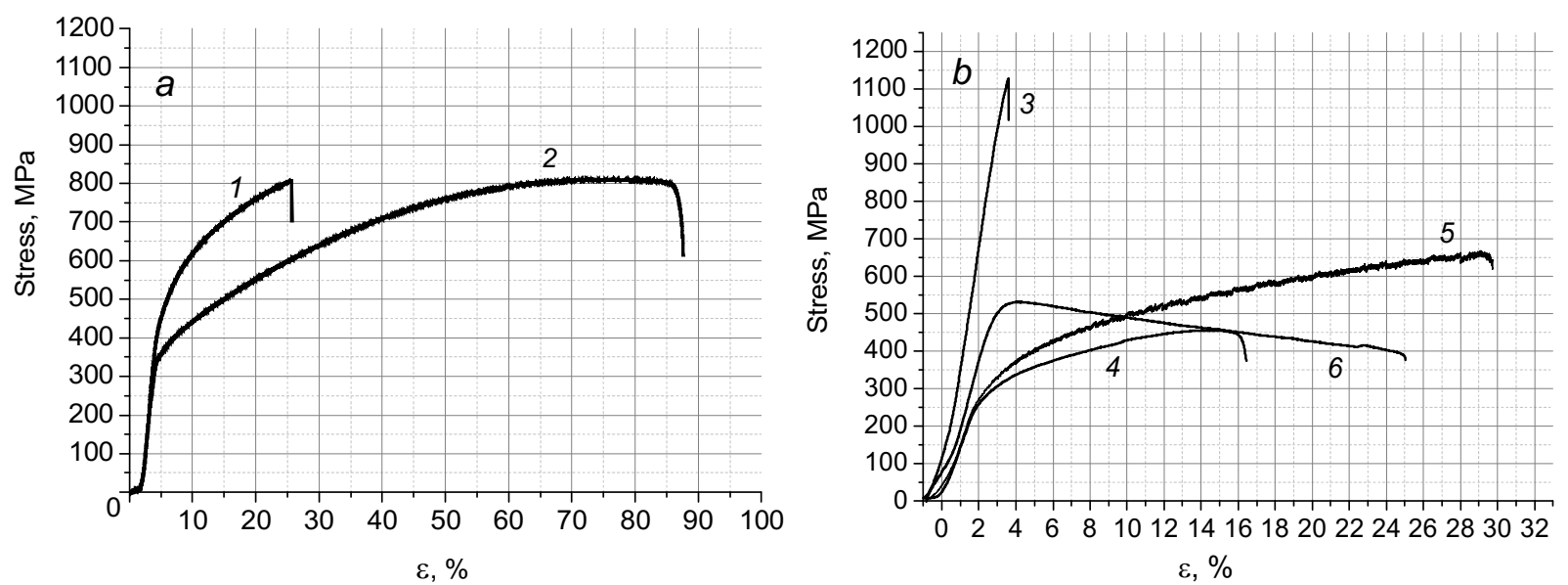

Fig. 4. Results of the experiments on hardening VZh171alloy specimens as a result of their tensile loading: $a$ - at room temperature in the initial (Curve 1) and nitrided (Curve 2) states, $b$ - at a temperature of $600^{\circ} \mathrm{C}$ in the nitrided (Curve 5) and nitrided rolled (Curve 3) states, and at a temperature of $800{ }^{\circ} \mathrm{C}$ in the nitrided (Curve 6 ) and nitrided rolled (Curve 4) states. The specimens during high-temperature testing were tempered for $1 \mathrm{~h}$ before tensile loading in order to form a predetermined structure.

and $800^{\circ} \mathrm{C}$. The specimens were held in the testing machine so that a structure corresponding to that formed during stationary annealing runs could be formed.

In the room temperature tests, the values of the ultimate tensile strength $\sigma_{\mathrm{UTS}}$ of the nitrided and non-nitrided specimens are practically the same (Fig. $4 a$ ). As a result of nitriding the values of the offset yield stress $\sigma_{0.2}$ increases from 340 to $440 \mathrm{MPa}$, and the relative elongation $\varepsilon$ considerably decreases from 84 to $22 \%$ (Table 1, Fig. $4 a$, Curves 1 and 2).

Table 1 presents the mechanical property data for the nitride VZh171alloy measured at the temperatures of 600 and $800^{\circ} \mathrm{C}$, including the cases after rolling deformation to $50 \%$ followed by annealing in the furnace before testing and testing at the annealing temperature. It is clear from Table 1 that the nitrided state after annealing at 600 and $800^{\circ} \mathrm{C}$ followed by testing at these temperatures demonstrates different plasticity and strength for similar deformation behavior (Fig. $4 b$, Curves 5 and 6 ). At the same time, a sharp decrease in strength compared to unannealed nitrided state of the specimen tested at room temperature (Fig. 4, Curve 2), could be attributed to the processes of dissolution of the disperse strengthening phase. It is likely that hardening of the alloy after its annealing at the temperature of $600^{\circ} \mathrm{C}$ occurs due to precipitation of the disperse chromium nitride particles, and its subsequent softening at the temperature of $800^{\circ} \mathrm{C}$ takes 
place due to dissolution of the nitride particles unstable at these and higher temperatures $\left(\mathrm{CrN}_{2}\right.$-phase is stable to $630^{\circ} \mathrm{C}$, $\mathrm{CrN}$ - up to $950^{\circ} \mathrm{C}$ ). However the decrease in plasticity from 22 to $13.8 \%$ in the case of annealing at $800^{\circ} \mathrm{C}$ for $1 \mathrm{~h}$ and subsequent testing at this temperature is still unclear. After a similar annealing run at $600^{\circ} \mathrm{C}$ and testing, the plasticity remains at the same level. Thus, annealing of the specimen in the nirtided state already at $800^{\circ} \mathrm{C}$ can have negative consequences, such as a decrease in plasticity.

On the other hand, deformation treatment with a subsequent annealing and testing at the annealing temperature leads to the formation of the most strengthened plastic state specifically in the case with annealing at $800^{\circ} \mathrm{C}$, while in the case of $600^{\circ} \mathrm{C}$ a nearly brittle state is formed (Fig. $4 b$, Curves 4 and 3). An increase in the offset yield strength is an important positive effect of the TMT carried out at $800^{\circ} \mathrm{C}$ after rolling.

\section{CONCLUSIONS}

1. An analysis of the influence of TMT (rolling deformation to a strain degree of $50 \%$, annealing at the temperatures of $600-1200^{\circ} \mathrm{C}, 1 \mathrm{~h}$ ) on the microstructure and phase composition of VZh171 alloy in the initial nonnitrided state and after bulk nitriding has been performed.

In non-nitrided alloy, the primary recrystallization and formation of fine-grained structure intensively occurs at the temperature above $1000^{\circ} \mathrm{C}$. At lower temperatures, particles of chromium carbides precipitate and grow on grain boundaries, which retards the grain-boundary motion and evolution of the grain shapes and sizes in the course of recrystallization. Annealing at the temperature of $1200^{\circ} \mathrm{C}$ leads to a complete dissolution of the chromium-based carbide particles, which favors the development of collective recrystallization.

2. An increase in the number of structural defects in the course of nitriding results in a decrease in the onset temperature of primary recrystallization to $800^{\circ} \mathrm{C}$. Annealing of the nitrided alloy at $1000^{\circ} \mathrm{C}$ leads to a complete dissolution of the chromium carbide particles and a partial dissolution of the chromium nitride particles, which promotes a transition to the stage of collective recrystallization. However, the stable titanium nitride particles remaining in structure retard the grain boundary motion during recrystallization. As a result, even at the annealing temperature of $1200^{\circ} \mathrm{C}$ the process of collective recrystallization is not essentially developed, and the microstructure remain relatively fine-grained (grain size 5-10 $\mu \mathrm{m}$ ).

3. Mechanical properties of the nitrided and non-nitrided alloy specimens have been investigated. It has been found out that nitriding does not significantly affect the alloy room-temperature strength.

4. An investigation of the mechanical properties of the nitrided state after anneals at 600 and $800^{\circ} \mathrm{C}$ with a subsequent testing at the annealing temperature allowed revealing a tendency of the alloy to embrittlement at the elevated temperatures. The revealed negative effect can be compensated by the application of TMT by rolling deformation to $50 \%$ with a subsequent annealing at $800^{\circ} \mathrm{C}$. The alloy specimens treated in this regime demonstrate the highest yield strength at a high plasticity among the states investigated in this work suitable for application in the service conditions.

This study has been performed with a financial support of the RFBR within a scientific project No. 18-0200760 and the Program of the basic research of the RAS Presidium No. 32 "Nanostructures: physics, chemistry, biology, fundamentals of technologies" and the Thematic map of the fundamental scientific research of IPCP of the RAS No. 0089-2019-0017.

\section{REFERENCES}

1. Yu. R. Kolobov, E. N. Kablov, E. V. Kozlov, et al., Structure and Properties of Intermetallic Materials with Nanophase Strengthening (Eds. E. N. Kablov and Yu. R. Kolobov) [in Russian], MISIS, Moscow (2008).

2. O. G. Ospennikov, Avia. Mater. Tekhn., No. 5, 19-36 (2012).

3. L. G. Petrova, Metal Sci. Heat Treatment, 37, No. 1-2, 41-47 (1995).

4. S. Y. Lee, Y. L. La, P. K. Liav, et al. Key Eng. Mater., 345-346, 287-290 (2007).

5. R. C. Reed, The Superalloys. Fundamentals and Applications, Cambridge University Press (2006). 
6. B. S. Lomberg, S. V. Ovsepyan, M. M. Bakradze, and I. S. Mazalov, Vestnik of N. E. Bauman MGTU. Ser. Mashinostroyeniye. Spets. Vyp. 98-103 (2011).

7. K. Kulawik, B. Dubiel, and A. Czyrska-Filemonowicz, Solid State Phenomena, 197, 131-136 (2013).

8. P. R. Soni, Mechanical Alloying: Fundamentals and Applications, Cambridge Int. Sci. Publ., Cambridge (2000).

9. L. G. Petrova, and O. V. Chudina, Metal Sci. Heat Treatment, No. 5, 31-41 (2010).

10. B. S. Lomberg, S. V. Ovsepyan, M. M. Bakradze, and I. S. Mazalov, Avia. Mater. Tekhn., No. 5, 52-57 (2012).

11. Yu. G. Bykov, S. V. Ovsepyan, I. S. Mazalov, and A. S. Romashov, Vestnik Dvigatelestr., No. 2, 246-250 (2012).

12. M. V. Akhmedzyanov, A. V. Skugarev, S. V. Ovsepyan, and I. S. Mazalov, Proizvodstvo Prokata, No. 1, 1417 (2015).

13. M. Fahrmann and S. K. Srivastava, JOM, 63, No. 2, 280-287 (2012).

14. A. A. Kodentsov, J. K. Kivilahti, and F. J. J. van Loo, Rare Metals, 25, Iss. 5, 501-511 (2006).

15. M. G. Krukovich, Metal Sci. Heat Treatment, No. 1, 24-31 (2004).

16. K. M. Eliasen, T. L. Christiansen, and A. J. Somers, Surf. Eng., 26, Iss. 4, 248-255 (2010).

17. L. G. Petrova, Metal Sci. Heat Treatment, No. 1, 18-24 (2004).

18. Yu. M. Lakhtin and Ya. D. Kogan, Theory and Technology of Nitriding [in Russian], Metallurgiya, Moscow (1991).

19. F. P. Ovsepyan, B. S. Bokstein, M. V. Akhmedzyanov, et al., Materialoved., No. 6, 21-25 (2014).

20. O. V. Kozlova, S. V. Ovsepyan, A. S. Pomelnikova and M. V. Akhmedzyanov, Vestnik of N. E. Bauman MGTU. Ser. Mashinostroyeniye, No. 6, 33-41 (2016).

21. E. A. Lukina, S. V. Ovsepyan, E. A. Davydova, and M. V. Akhmedzyanov, Tsvetn. Metally, No. 7(883), 76$82(2016)$.

22. V. V. Slezov and D. M. Levin, Phys. Solid State, 12, No. 12, 1748-1752 (1970). 